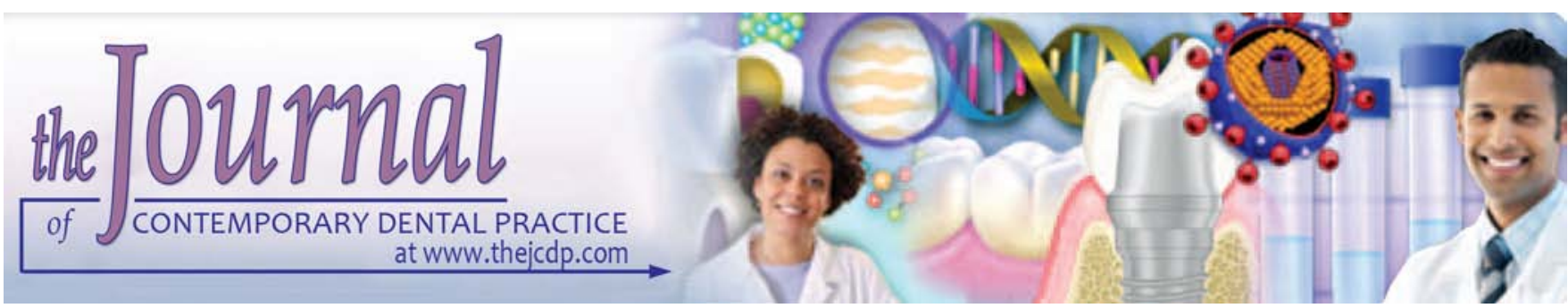

\title{
Antibacterial Potential of $2.5 \%$ Sodium Hypochlorite in Distinct Irrigation Protocols on Enterococcus faecalis Biofilm
}

\author{
${ }^{1}$ Denise Ramos Silveira Alves, ${ }^{2}$ Rodrigo Sanches Cunha, ${ }^{3}$ Carlos Eduardo da Silveira Bueno \\ ${ }^{4}$ Ana Helena Gonçalves de Alencar, ${ }^{5}$ Cyntia Rodrigues de Araújo Estrela \\ ${ }^{6}$ Tatiane Oliveira dos Santos, ${ }^{7}$ Carlos Estrela
}

\begin{abstract}
Objective: The aim of this study was to evaluate the effect of irrigation methods on antibacterial potential of $2.5 \% \mathrm{NaOCl}$ on Enterococcus faecalis biofilm.
\end{abstract}

Materials and methods: Enterococcus faecalis biofilms were prepared during 60 days on 48 human root canals and randomized into control and experimental groups using positive and negative pressure irrigation. Bacterial growth was analyzed using turbidity of culture medium followed by UV spectrophotometry, and scanning electron microscopy (SEM) analyses were performed. Mean and standard deviations were used for evaluate the mean optical densities associated to the number of bacteria present culture, and Scheirer-Ray-Hare (an extension of the Kruskal-Wallis test) and Tamhane test to analyze the SEM images in the groups and thirds. Significance was set at $5 \%$.

Results: Enterococcus faecalis was still present after root canal cleaning regardless of irrigation methods or bacterial identification methods.

Conclusion: Positive and negative pressure irrigation protocols using $2.5 \% \mathrm{NaOCl}$ show a similar capacity to reduce $E$. faecalis in infected root canals.

Keywords: Sodium hypochlorite, Biofilm, Irrigating solution, Root canal infection, Negative pressure system.

1,4,5,7 Department of Stomatologic Sciences, Federal University of Goiás, Goiânia, State of Goiás, Brazil

${ }^{2}$ Department of Conservative Dentistry, University of Manitoba Canada

${ }^{3}$ Department of Conservative Dentistry, Sao Leopoldo Mandic School of Dentistry, Campinas, São Paulo, Brazil

${ }^{6}$ Department of Physics, Federal University of Goiás, Goiânia State of Goiás, Brazil

Corresponding Author: Denise Ramos Silveira Alves Professor, Department of Stomatologic Sciences, Federal University of Goiás, Praça Universitária s/n, Sector Universitário CEP: 74605-220, Goiânia, State of Goiás, Brazil, e-mail: denisealves1@brturbo.com.br
How to cite this article: Alves DRS, Cunha RS, da Silveira Bueno CE, de Alencar AHG, de Araújo Estrela CR, dos Santos TO, Estrela C. Antibacterial Potential of 2.5\% Sodium Hypochlorite in Distinct Irrigation Protocols on Enterococcus faecalis Biofilm. J Contemp Dent Pract 2015;16(5):340-346.

\section{Source of support: Nil}

\section{Conflict of interest: None}

\section{INTRODUCTION}

The treatment of endodontic infection has better chances of success when an adequate cleaning and shaping protocol is adopted. The root canal microenvironment favors the adhesion of several bacterial species to the dentin surface, as well as the formation of a dense biofilm resistant to antimicrobial treatment, often inaccessible to endodontic instruments and irrigants. ${ }^{1}$ Areas that remain untouched canal preparation ${ }^{2}$ may lead to root canal and dentinal tubule infection. ${ }^{3,4}$

Of the different root canal irrigants suggested for infection control, 5,6 sodium hypochlorite is the most common. ${ }^{5-9}$ Sodium hypochlorite leads to biosynthetic changes in cell metabolism, phospholipid destruction and chloramine formation, which affects cell metabolism and oxidation and results in irreversible enzymatic inactivation in bacteria and lipid and fatty acid degradation. ${ }^{9}$ However, its irrigant efficacy depends on its direct contact with microorganisms. Irrigation volume, as well as exposure time and irrigation protocol, is important. $5,7,10$

In the conventional irrigation technique, a syringe is used, and the pressure on the plunger is regulated by the operator. ${ }^{11}$ The needle tip is placed 2 to $3 \mathrm{~mm}$ from the apex, and the irrigant is passively released. The solution does not reach farther than $1 \mathrm{~mm}$ beyond the needle tip and seems ineffective in cleaning the apical third of the root canal. ${ }^{12}$ When the needle is locked in the apical 
region or the pressure is not carefully regulated, there is greater probability of solution extrusion, which may result in a highly complex accident. ${ }^{11,13,28}$

Recent studies have shown that negative pressure irrigation seems to have a greater cleaning potential than positive pressure irrigation. ${ }^{11-19}$ Negative pressure seems to promote greater interaction between the irrigant and the canal walls. ${ }^{11,14}$ EndoVac $^{\circledR}$ (Discus Dental, Culier City, $\mathrm{CA}$ ) is a negative pressure irrigation system designed to enhance the penetration of the irrigant solution into the apical portion of the canal and to favor debris removal. The system is connected to a high-power suction pump, and the liquid flows in negative pressure. ${ }^{12}$ Studies that compared it with conventional needle irrigation systems found that the EndoVac ${ }^{\circledR}$ carries a greater irrigant flow to the apical third and reduces the probability of overflow. Reverse flow promotes a better cleaning of the apical region and reduces post-treatment pain. ${ }^{6,7,12,17}$

This study compared the effect of positive and negative pressure irrigation on the antimicrobial effectiveness of $2.5 \%$ sodium hypochlorite in E. faecalis biofilm.

\section{MATERIALS AND METHODS}

The method of this study was based on the procedures previously described by Estrela et al. ${ }^{20,21}$

\section{Biological Indicator}

A gram-positive facultative cocci, E. faecalis (ATCC 29212) was used in this assay. The bacterial strain was inoculated in $7 \mathrm{ml}$ of brain heart infusion broth (BHI; Difco Laboratories, Detroit, MI, USA) and incubated at $37^{\circ} \mathrm{C}$ for 24 hours. The experimental suspensions were prepared by cultivating the biological indicator on the surface of BHI agar (Difco Laboratories, Detroit, MI, USA), following the same incubation conditions. The bacterial cells were resuspended in saline solution to reach a final concentration of about $3 \times 10^{8}$ cells $/ \mathrm{ml}$ adjusted to no. 1 McFarland turbidity standard. The bacterial concentration before and after use of the irrigant was interpreted using an UV spectrophotometer (Model Nova 1600 UV, Piracicaba, SP, Brazil) regulated to $\lambda=600$ nanometers ( $\mathrm{nm}$ ) wave-length and no. 1 McFarland standard, which corresponds to $0.137 \mathrm{~nm}$ absorbance after the zero reading of the sterile saline solution.

\section{Samples Preparation}

A total of 48 extracted maxillary central incisors with intact cementum were selected for this assay. The teeth were removed from storage in $0.2 \%$ thymol solution and were immerzed in $5 \% \mathrm{NaOCl}$ for 30 minutes to remove organic tissues. Buccolingual and proximal radiographs were taken using periapical films (Eastman Kodak Co., Rochester, NY, USA) to confirm the presence of a single canal and the absence of anatomical variations. The study was approved by the Institutional Ethics Committee.

Standard access cavities were prepared and apical patency was achieved with a K-Flex \#15 (Maillefer, Ballaigues, Switzerland) and confirmed by direct viewing of the instrument tip in the apical foramen. The anatomical diameter of root canal was standardized from the initial preparation with BioRace system (FKG Dentaire, La Chaux-de-Fonds, Switzerland) BR0\#25/0.08, BR1\#15/0.05, BR2\#25/0.04, BR3\#25/0.06, BR4\#35/0.04, BR5\#40/0.04 and BR5C\#40/0.02 were used for root canal preparation (RCP) and anatomical diameter standardized. During RCP, the canals were irrigated with $3 \mathrm{ml}$ of $2.5 \% \mathrm{NaOCl}$ at each change of instrument using an Ultradent syringe and 0.30 mm Navitip needle (Ultradent Products Inc., South, South Jordan, UT). The $\mathrm{NaOCl}$ solution was prepared shortly before use. The crowns were removed with a fissure bur (EndoZ, Maillefer, Ballaigues, Switzerland) under continuous air/water spray, in a high-speed handpiece at a $90^{\circ}$ angle to the long axis of the tooth, and tooth length was standardized to $16 \mathrm{~mm}$ (from root apex to coronal border). Root canals were dried and filled with 17\% EDTA ( $\mathrm{pH}$ 7.2) for 3 minutes for smear layer removal. After RCP, the teeth were autoclaved for 30 minutes at $120^{\circ} \mathrm{C}$.

\section{Experimental Strategy}

A split platform was used during inoculation with the bacterial strain. The coronal portion of the root canal of each tooth was connected to the cut end of a $1.5 \mathrm{ml}$ polypropylene Eppendorf tube using a cyanoacrylate adhesive to prevent leakage at the connection. The tooth-tube connections were entirely coated with two layers of nail polish. The specimens (teeth coupled with polypropylene tubes) were sterilized in $5 \% \mathrm{NaOCl}$ for 30 minutes and then placed into the culture medium (BHI). To ensure disinfection, the test apparatus was incubated at $37^{\circ} \mathrm{C}$ for 24 hours. No growth was observed after that time. Five milliliters of sterile BHI were mixed with $5 \mathrm{ml}$ of the bacterial inoculum, and the experimental and positive control groups were inoculated with $E$. faecalis for 60 days, using sterilized syringes whose volume was sufficient to fill the canal. This procedure was repeated every 72 hours, always using 24-hour pure cultures prepared and adjusted to no. $1 \mathrm{McF}$ arland turbidity standard. The teeth were kept in a humid environment at $37^{\circ} \mathrm{C}$.

After contamination, the root canals were dried and refilled with sterile distilled water. Each sample was collected by using three \#40 paper points applied for 3 
minutes. The points were then individually transported and immersed in $7 \mathrm{ml}$ of Letheen Broth (LB; Difco Laboratories, Detroit, MI, USA) and a medium with neutralizers [Lecithin, Tween 80 and sodium thiosulfate] at appropriate concentrations, and incubated at $37^{\circ} \mathrm{C}$ for 48 hours in a reduced oxygen atmosphere. After bacterial growth was confirmed, the experimental groups were prepared.

The teeth were randomly assigned to four experimental and two control groups according to irrigation protocol and root canal preparation: (1) Negative pressure irrigation (EndoVac ${ }^{\circledR}$, Discus Dental, Culier City, CA) with $2.5 \% \mathrm{NaOCl}$ associated with RCP; (2) Negative pressure irrigation with $2.5 \% \mathrm{NaOCl}$ but no instrumentation; (3) Positive pressure irrigation with $2.5 \% \mathrm{NaOCl}$ associated with RCP; (4) Positive pressure irrigation with $2.5 \% \mathrm{NaOCl}$ but no instrumentation; (5) Positive control; (6) Negative control.

Five teeth of each group were evaluated by culture and three by scanning electron microscopy (SEM) (Table 1). In all teeth, the root canals were dried and filled with $17 \%$ EDTA ( $\mathrm{pH} 7.2$ ) for 3 minutes for smear layer removal. In the groups 1 and 3, specimens were prepared using the BioRace system (FKG Dentaire, Swiss) following the sequence BR5C \#40/0.02, BR6 \#50/0.04 and BR7 \#60/0.02. Each NiTi instrument was used in only five canals. In groups 1 and 2, EndoVac ${ }^{\circledR}$ was used according to the manufacturer's recommendations. All the samples were irrigated with the same volume of irrigants. Irrigation was performed during canal shaping with the master point attached to the syringe and connected to a vacuum suction system. Initial irrigation with $10 \mathrm{ml}$ of $2.5 \%$ $\mathrm{NaOCl}$ was performed with the master point placed at the entrance to the root canal before and after instrumentation with BR5C \#40/0.02. After instrumentation with BR6 \#50./0.04 and BR7 \#60/0.02, irrigation was performed using an ISO \#55.02 taper macrocannula connected to the titanium handpiece and placed at a length of $10.5 \mathrm{~mm}$ for 30 seconds, under continuous irrigation using the

Table 1: Distribution of irrigation methods, with or without NiTi RP, using culture and scanning electron microscopy

\begin{tabular}{llll}
\hline Groups & Methods & $\begin{array}{l}\text { Culture } \\
(n=30)\end{array}$ & $\begin{array}{l}\text { SEM } \\
(n=18)\end{array}$ \\
\hline 1 & NPI + RCP (EndoVac, 2.5\% NaOCl) & 5 & 3 \\
2 & NPI (EndoVac, 2.5\% NaOCl) & 5 & 3 \\
3 & PPI + RCP (Conventional, 2.5\% & 5 & 3 \\
& NaOCl) & & \\
4 & PPI (Conventional, 2.5\% NaOCl) & 5 & 3 \\
5 & Positive control & 5 & 3 \\
6 & Negative control & 5 & 3 \\
\hline
\end{tabular}

NPI: Negative-pressure irrigation; PPI: Positive-pressure irrigation; RCP: Root canal preparation system's syringe. After instrumentation using the BR7 \#60/0.02, irrigation was performed using a $0.32 \mathrm{~mm}$ micro cannula connected to a digital titanium piece and placed at the working length for 6 seconds. It was then moved $2 \mathrm{~mm}$ and kept in this position for 6 more seconds, when it was once again moved back to the working length and kept there for 6 seconds.

After RCP, the tooth was dried with \#60 sterile absorbent paper points and filled with $3 \mathrm{ml}$ of $17 \%$ EDTA kept under agitation with a manual instrument for 3 minutes. Then, the root canal was irrigated with the microcannula as described above. Once the first group was prepared, the total volume of $\mathrm{NaOCl}$ solution was calculated so that the same volume would be used during the whole experiment. In groups 3 and 4, conventional irrigation was performed with an Ultradent $5 \mathrm{ml}$ syringe and $0.30 \mathrm{~mm}$ Navitips irrigation needle (Ultradent Products Inc., South, South Jordan, UT, USA) placed at $12 \mathrm{~mm}$. Initial irrigation was performed with $5 \mathrm{ml}$ of $2.5 \%$ $\mathrm{NaOCl}$ with short up and down movements. At every instrument change, irrigation was repeated with $7 \mathrm{ml}$ of the solution. When NiTi RP was completed, the tooth was dried with a \#60 sterile absorbent paper point and filled with $3 \mathrm{ml}$ of 17\% EDTA kept under agitation with a manual instrument for 3 minutes. Then, the root canal was irrigated with $7 \mathrm{ml}$ of $2.5 \% \mathrm{NaOCl}$.

The negative control group was used to test sample sterility, and the positive control group, to ascertain bacterial viability during the experiment. For the 60 days of root canal contamination, five noninoculated teeth were incubated at $37^{\circ} \mathrm{C}$ as an aseptic control, and five teeth were inoculated with $E$. faecalis in similar environmental conditions.

After the irrigation methods and NiTi RP were completed, an additional irrigation with $5 \mathrm{ml}$ of sterile distilled water was performed using a syringe. The root canals were dried, filled with sterile distilled water, and then dried again as described above. All samples were collected using three paper points. The points were individually transported, immersed in $7 \mathrm{ml}$ of LB (Difco Laboratories, Detroit, MI, USA) and a medium containing a neutralizer at appropriate concentrations, and incubated at $37^{\circ} \mathrm{C}$ for 48 hours in a reduced oxygen atmosphere. After 72 hours, new material was collected, as described below. After the evaluation of changes in the culture medium, an inoculum of $0.1 \mathrm{ml}$ from the medium was transferred to $7 \mathrm{ml}$ of $\mathrm{BHI}$ and incubated at $37^{\circ} \mathrm{C}$ for 48 hours. The gram staining of the BHI culture was used to confirm E. faecalis contamination. All the collections were carried out under aseptic conditions. ${ }^{20}$ 
Bacterial growth was analyzed by turbidity of the culture medium and then analyzed under UV spectrophotometry at 20 minutes and at 72 hours. The measurement of culture medium optical density was proportional to the number of bacteria present. Samples were taken at random and cultivated to check for E. faecalis purity, as described in an earlier study. ${ }^{21}$

\section{Preparation for SEM Analysis}

Three teeth of each group were analyzed under SEM after 72 hours of experimental protocols. The teeth were fixed in buffered formalin solution for a week and then dehydrated in increasing solutions of 70, 95 and $100 \%$ ethanol with two changes of each solution at each 30 minutes. In three teeth of each group, longitudinal grooves were made along the entire length of each root by carefully using a metal disk under water refrigeration (KG Sorensen Ind. Com., São Paulo, SP, Brazil) and a surgical chisel to create a buccolingual split along the long axis to expose the entire extent of the root canal. The teeth were sputter-coated for SEM analysis (JEOL, JSM-6360LV, Tokyo, Japan). Initially, the specimens were analyzed by navigating the images to visualize bacterial contamination at different magnifications. For the comparative analysis between groups, two SEM micrographs were obtained from each third. The root canal was measured, and the central part of each middle third was evaluated.

Three independent and skillful endodontists examined the SEM after thoroughly discussing the established interpretation criteria (described in a following paragraph). Approximately, $10 \%$ of total of images were initially examined by the blinded examiners for calibration and standardization of the evaluation criteria. When a consensus was not reached after two examiners evaluated the images, the third made the final decision.

The images were then analyzed to detect the presence or absence of contamination and debris on root canal surface using the following scores: (1) root canal surface completely clean; (2) few areas covered by E. faecalis colonizing root dentin surface; (3) most areas covered by $E$. faecalis colonizing root dentin surface; (4) root canal surface completely contaminated.

The data were statistically analyzed using the SPSS for Windows 19 (SPSS Inc., Chicago, IL, USA). Results were described by using mean and standard deviations for evaluating the mean optical densities associated to the number of bacteria present culture, and ScheirerRay-Hare (an extension of the Kruskal-Wallis test) and Tamhane test to analyzed the SEM images in the groups and thirds. Significance was set at 5\%.

\section{RESULTS}

Enterococcus faecalis was found after cleaning, regardless of irrigation method and time point. Mean optical densities at both assessment time points revealed a significant bacterial reduction compared with positive control and no statistically significant differences when compared with each other $(p>0.05)$ (Table 2).

The number of bacteria decreased after irrigation methods (Figs 1A to H). Scheirer-Ray-Hare test was used to evaluate two factors (groups and thirds) with interactions. It detected differences just for the thirds $(\mathrm{p}<0.05)$. In the thirds analysis (Tamhane test), it was verified

Table 2: Mean optical densities associate to the number of bacteria present

\begin{tabular}{|c|c|c|c|c|}
\hline Protocols & $20 \mathrm{~min}$ & $\begin{array}{l}\text { Mean/SD } \\
\text { optical density } \\
\text { of medium }\end{array}$ & $72 h$ & $\begin{array}{l}\text { Mean/SD } \\
\text { optical density } \\
\text { of medium }\end{array}$ \\
\hline G1 & +++ & $0.071 \pm 0.067^{\star}$ & +++ & $0.095 \pm 0.023^{\star}$ \\
\hline $\mathrm{G} 2$ & +++ & $0.034 \pm 0.013$ & +++ & $0.028 \pm 0.014$ \\
\hline G3 & +++ & $0.030 \pm 0.011^{*}$ & +++ & $0.098 \pm 0.070^{*}$ \\
\hline G4 & +++ & $0.026 \pm 0.024$ & +++ & $0.060 \pm 0.048$ \\
\hline G5 & +++ & $0.208 \pm 0.064$ & +++ & $0.245 \pm 0.072$ \\
\hline G6 & - - - & 0.000 & -- & 0.000 \\
\hline
\end{tabular}

(+++: presence of bacteria; - - -: absence of bacteria; $p>0.05)$; *data from reference,$^{20}$ group 3-4. SD: Standard deviation

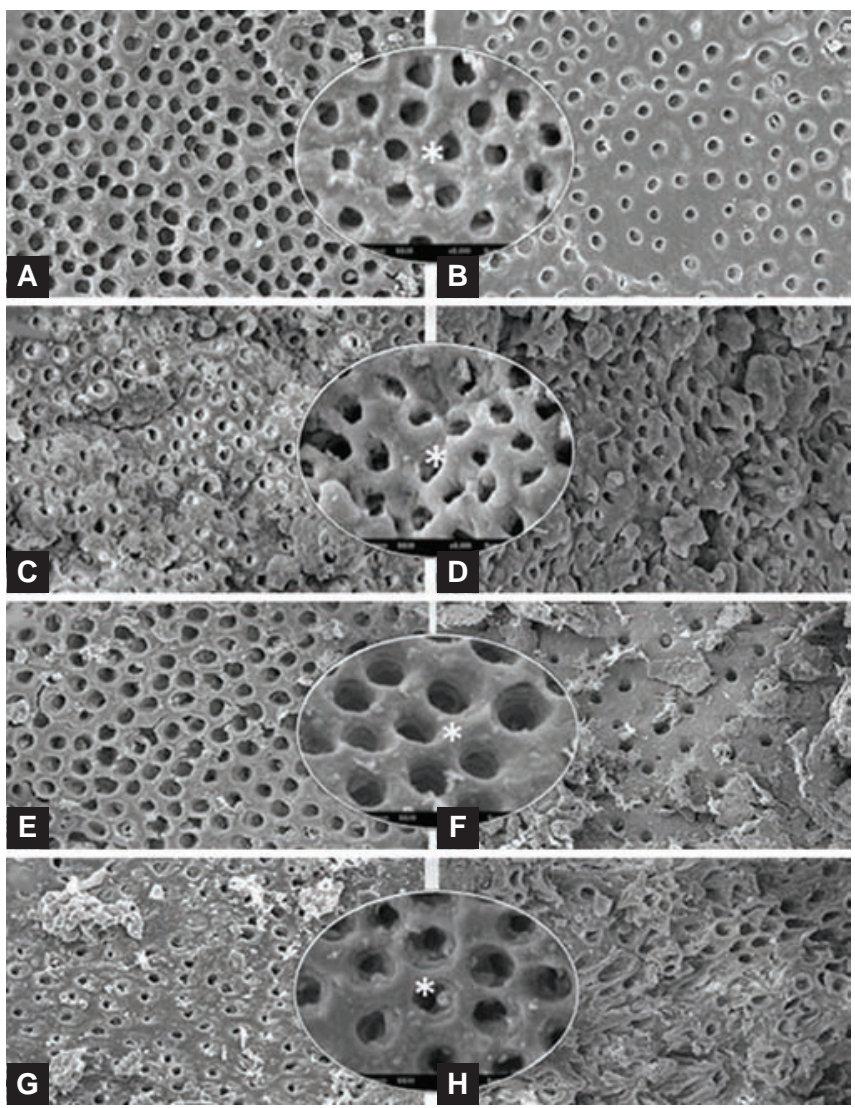

Figs $1 \mathrm{~A}$ to $\mathrm{H}$ : (A and $\mathrm{B}) \mathrm{NPI}+\mathrm{RCP}$, cervical and apical thirds, SEM $1,600 \times\left({ }^{\star} 5000 \times\right) ;(C$ and D) NPI, cervical and apical thirds, SEM $1,600 \times\left({ }^{*} 5000 \times\right.$ in cervical third); (E and F). PPI + RCP, cervical and apical thirds, SEM 1,600 $\times\left({ }^{*} 5000 \times\right) ;(\mathrm{G}$ and H) PPI, cervical and apical thirds, SEM 1,600 $\times\left({ }^{\star} 5000 \times\right.$ in cervical third $)$. 
significant differences between cervical and apical third $(\mathrm{p}<0.05)$, and no statistically significant differences when compared apical and middle thirds ( $p>0.05$ ), and cervical and middle thirds $(\mathrm{p}>0.05)$.

\section{DISCUSSION}

Cleaning root canals infected by E. faecalis and examined after 60 days was associated with both positive and negative pressure irrigation in reducing the number of bacteria. Positive and negative pressure irrigation protocols using $2.5 \% \mathrm{NaOCl}$ show a similar capacity to reduce $E$. faecalis in infected root canals.

The negative apical pressure irrigation method uses a high-power suction system, and irrigation is performed with a large volume of irrigant solution. This system injects the irrigant flow deeper into the root canal, which results in better cleaning than that achieved when a conventional irrigation method is used. ${ }^{14}$ Positive pressure is the system most often used because of its simplicity. ${ }^{19}$ Some studies showed that, in addition to a rational selection of irrigants, volume and adequate flow along the root canal walls are essential for cleaning. ${ }^{19,22-24}$ When negative pressure is used, a higher volume of irrigant is delivered to the root canal at time intervals that are appropriate to the technique. ${ }^{14}$ Irrigant volume is directly associated with the effectiveness of root canal disinfection, ${ }^{25-27}$ but few studies described what volume should be injected when positive and negative pressure methods are compared..$^{27}$ To standardize this variable, irrigant volume was the same for all the experimental groups in the present study, as in a previous study. ${ }^{16}$

Several irrigants have been used in endodontics to control or eliminate infection. Sodium hypochlorite, used for decades, is an antimicrobial agent. ${ }^{5-10}$ In this study, some factors were considered when selecting the $\mathrm{NaOCl}$ solution, which was prepared immediately before use and at a concentration of $2.5 \%$. A recent study conducted to evaluate the effect of concentration, time of exposure, and temperature on the penetration of $\mathrm{NaOCl}$ into dentinal tubules. The shortest penetration $(77 \mu \mathrm{m})$ was measured after incubation with $1 \% \mathrm{NaOCl}$ for 2 minutes at room temperature. The deepest penetration $(300 \mu \mathrm{m})$ was obtained with $6 \% \mathrm{NaOCl}$ for 20 minutes at $45^{\circ} \mathrm{C}$. After the initial penetration during the first 2 minutes, the depth of penetration doubled in the next 18 minutes of exposure. Temperature had a modest effect on the depth of penetration within each group and was not statistically significant in most cases. Depth of penetration increased with increasing hypochlorite concentration, but the differences were small. Within each time group, depth of penetration for $1 \% \mathrm{NaOCl}$ was about 50 to $80 \%$ of the values for the $6 \%$ solution.
Studies that assessed negative pressure irrigation confirmed its capacity of removing debris removal and the safety associated with irrigant extrusion to the periapical region. ${ }^{14-16,29,30}$ The efficacy of this system in reducing microbial infection was also confirmed in comparisons with the conventional system using an irrigation needle. ${ }^{11,19,31}$ In those studies, root canal surfaces were contaminated for 30 days. Hockett et al ${ }^{11}$ found greater microbial reduction using negative than positive pressure. The root canals were instrumented before contamination and, during the irrigation protocol, no instrumentation was performed. In current study, the systems were tested in two groups with NiTi RP and in two groups without instrumentation. NiTi RP was performed using BR7 \#60/0.02 to remove more infected dentin mechanically and increase root canal diameter, which resulted in a greater flow of irrigant solution along the walls to the apical portion and improved the chemical action of the irrigant. Although no differences were found between the groups with and without NiTi RP because of the study conditions and the groups of teeth under study, the mechanical action of the instrument is an essential aid in disrupting biofilm. A proper anatomical diameter at the apical third extends and improves cleaning. The difference between results might be explained by method differences.

The analysis of contamination before and after cleaning using turbidity of the culture medium and UV spectrophotometry revealed that the amounts of bacteria recovered after irrigation were similar for different protocols. ${ }^{22}$ In the present study, high magnification SEM images showed that the walls of the different root canal thirds were clean in the comparison of the protocols tested for bacterial control. However, the results of the microbiological analysis using culture suggested the presence of viable bacteria, which might be in the dentinal tubules or canal ramifications.

Root canal infection lasted 60 days ${ }^{21}$ which is sufficient for E. faecalis to contaminate the root canal surface and invade dentinal tubules. Enterococcus faecalis was selected because it is an important biological indicator used in previous studies and susceptible to antimicrobials. Also, it can survive in the root canal without support of other bacterial species, thrives in a hostile environment and grows easily. 3,6,9,10,21,31,32

Enterococcus faecalis adapts to the environmental changes after endodontic treatment and remains as a pathogen in the root canal system, which makes its elimination difficult. ${ }^{21,32}$ In the present study, none of the protocols eradicated microorganism from the root canals. These findings are in accordance with previous studies, which showed microbial persistence after use of potent irrigants in infected root canals. $1,3,4,7,9,10,20$ 
The extracted single-rooted human teeth were used to simulate the clinical environment. Dentin was the primary substrate for bacterial adhesion as there is evidence of its interaction with irrigants. ${ }^{19,20,32}$ In this study, the purpose was not to create an open or closed system at the apical foramen because it did not aim to evaluate differences in cleaning between root canal thirds. The main objective of this study was to evaluate whether the two methods were able to eliminate E. faecalis from the root canal.

The irrigation needle was placed $3 \mathrm{~mm}$ short of the working length to simulate safe clinical procedures. During irrigation, short up-and-down movements were performed respecting the limit of the needle at $13 \mathrm{~mm}$. This technique was similar to those reported in previous studies. ${ }^{11,14,17,30}$ Based on this protocol and the irrigant volume used, the usual irrigation groups had similar levels of microbial control in the negative pressure groups. Despite the volume provided by the negative pressure system, the macrocannula aspirated part of the irrigant that remained in the coronal third of the root canal before it reached the tip of the microcannula. ${ }^{18,30}$ Heilborn et al compared the efficacy of root canal cleaning and measured irrigant volume in the apical third of teeth cleaned using the negative and positive pressure systems at two time points. In the negative pressure system group, debris cleaning was better in the apical third at a short exposure time. Irrigants can penetrate dentinal tubules, but their concentration may not be sufficient to inactivate all microorganisms. ${ }^{33}$ Bacteria in the deeper layers of the dentinal tubules and other anatomical recesses seem to be protected from instrumentation and irrigation, and bacterial removal or eradication is difficult. ${ }^{19}$ The findings of the present study are in agreement with those reported in previous studies, $19,20,34$ which concluded that the effect of antimicrobials may be short of their potential when they do not reach the target microorganism. In recent study, Pawar et $\mathrm{al}^{35}$ developed a randomized, controlled, prospective clinical study to determine whether the use of EndoVac irrigation was more efficient compared with standard needle irrigation in obtaining canals from which microbes could not be cultivated. The results showed that the antimicrobial efficacy of EndoVac irrigation was comparable to that of standard irrigation.

One of the limitations of this study was that the teeth used were anterior human teeth (maxillary central incisors), whose root canals have a representative anatomic diameter in comparison with other dental groups. The challenge remains to make sure that the irrigant acts on all root canal surfaces, at a volume and length of time that neutralizes bacteria and helps the instruments to disrupt the biofilm, considering the complexity of morphology in all dental groups. Technological advances result in several devices that facilitate root canal cleaning and may improve the rate of endodontic treatment success. Further studies should define new irrigation guidelines for the treatment of endodontic infections.

\section{CONCLUSION}

Positive or negative pressure irrigations using 2.5\% sodium hypochlorite reduced $E$. faecalis infection in root canals.

\section{REFERENCES}

1. Nair PN, Henry S, Cano V, Vera J. Microbial status of apical root canal system of human mandibular first molars with primary apical periodontitis after 'one-visit' endodontic treatment. Oral Surg Oral Med Oral Pathol Oral Radiol Endod 2005;99(2):231-252.

2. Paqué F, Laib A, Gautschi H, Zehnder M. Hard-tissue debris accumulation analysis by high-resolution computed tomography scans. J Endod 2009;35(7):1044-1047.

3. Vera J, Siqueira Jr JF, Ricucci D, Loghin S, Fernández N, Flores B, Cruz AG. One-versus two-visit endodontic treatment of teeth with apical periodontitis: a histobacteriologic study. J Endod 2012;38(8):1040-1052.

4. Vieira AR, Siqueira JF Jr, Ricucci D, Lopes WS. Dentinal tubule infection as the cause of recurrent disease and late endodontic treatment failure: a case report. J Endod 2012;38(2):250-254.

5. Peters OA. Current challenges and concepts in the preparation of root canal systems: a review. J Endod 2004;30(8):559-567.

6. Zehnder M. Root canal irrigants. J Endod 2006;32(5):389-398.

7. Estrela CR, Estrela C, Reis C, Bammann LL, Pécora JD. Control of microorganisms in vitro by endodontic irrigants. Braz Dent J 2003;14(3):187-192.

8. Torabinejad M, Khademi AA, Babagoli J, Cho Y, Ben Johnson W, Bozhilov K, Kim J, Shabahang S. A new solution for the removal of the smear layer. J Endod 2003;29(3):170-175.

9. Estrela C, Estrela CR, Barbin EL, Spanó JC, Marchesan MA, Pécora JD. Mechanism of action of sodium hypochlorite. Braz Dent J 2002;13(2):113-117.

10. Roças IN, Siqueira JF Jr. Comparison of the in vivo antimicrobial effectiveness of sodium hypochlorite and chlorhexidine used as root canal irrigants: a molecular microbiology study. J Endod 2011;37(2):143-150.

11. Hockett JL, Dommisch JK, Johnson JD, Cohenca N. Antimicrobial efficacy of two irrigation techniques in tapered and non tapered canal preparations: an in vitro study. J Endod 2008;34(11):1374-1377.

12. Parente JM, Loushine RJ, Susin L, Gu L, Looney SW, Weller RN, Pashley DH, Tay FR. Root canal debridement using manual dynamic agitation or the EndoVac for final irrigation in a closed system and an open system. Int Endod J 2010;43(11):1001-1012.

13. Boutsioukis C, Lambrianidis T, Verhaagen B, Versluis M, Kastrinakis E, Wesselink PR, van der Sluis LW. The effect of needle-insertion depth on the irrigant flow in the root canal: evaluation using an unsteady computational fluid dynamics model. J Endod 2010;36(10):1664-1668. 
14. Nielsen BA, Baumgartner JC. Comparison of the EndoVac system to needle irrigation of root canals. J Endod 2007;33(5): 611-615.

15. Siu C, Baumgartner JC. Comparison of the debridement efficacy of the EndoVac irrigation system and conventional needle root canal irrigation in vivo. J Endod 2010;36(11): 1782-1785.

16. Mitchell RP, Yang SE, Baumgartner JC. Comparison of apical extrusion of $\mathrm{NaOCl}$ using the EndoVac or needle irrigation of root canals. J Endod 2010;36(2):338-341.

17. Gondim E Jr, Setzer FC, Dos Carmo CB, Kim S. Postoperative pain after the application of two different irrigation devices in a prospective randomized clinical trial. J Endod 2010;36(8):1295-1301.

18. Heilborn C, Reynolds K, Johnson JD, Cohenca N. Cleaning efficacy of an apical negative-pressure irrigation system at different exposure times. Quintessence Int 2010;41(9):759-767.

19. Miller TA, Baumgartner JC. Comparison of the antimicrobial efficacy of irrigation using the EndoVac to endodontic needle delivery. J Endod 2010;36(3):509-511.

20. Estrela C, Sousa-Neto MD, Alves DRS, Alencar AHG, Santos TO, Pécora JD. A preliminary study of the antibacterial potential of cetylpyridinium chloride in root canals infected by E. faecalis. Braz Dent J 2012; 23(6):645-653.

21. Estrela C, Estrela CR, Decurcio DA, Hollanda AC, Silva JA. Antimicrobial efficacy of ozonated water, gaseous ozone, sodium hypochlorite and chlorhexidine in infected human root canals. Int Endod J 2007;40(2):85-93.

22. Heling I, Chandler NP. Antimicrobial effect of irrigant combinations within dentinal tubules. Int Endod J 1998; 31(1):8-14.

23. Gregorio C, Estevez R, Cisneros R, Paranjpe A, Cohenca N. Efficacy of different irrigation and activation systems on the penetration of sodium hypochlorite into simulated lateral canals and up to working length: an in vitro study. J Endod 2010;36(7):1216-1221.

24. Sedgley CM, Nagel AC, Hall D, Applegate B. Influence of irrigant needle depth in removing bioluminescent bacteria inoculated into instrumented root canals using real-time imaging in vitro. Int Endod J 2005;38(2):97-104.

25. Zou L, Shen Y, Haapasalo M. Penetration of sodium hypochlorite into dentin. J Endod 2010;36(5):793-796.

26. Howard RK, Kirkpatrick TC, Rutledge RE, Yaccino JM. Comparison of debris removal with three different irrigation techniques. J Endod 2011;37(9):1301-1305.

27. Brunson M, Heilborn C, Johnson DJ, Cohenca N. Effect of apical preparation size and preparation taper on irrigant volume delivered by using negative pressure irrigation system. J Endod 2010;36(4):721-724.

28. Desai $\mathrm{P}$, Himel V. Comparative safety of various intracanal irrigation systems. J Endod 2009;35(4):545-549.

29. Munoz HR, Camacho-Cuadra K. In vivo efficacy of three different endodontic irrigation systems for irrigant delivery to working length of mesial canals of mandibular molars. J Endod 2012;38(4):445-448.

30. Brito PR, Souza LC, Machado de Oliveira JC, Alves FR, De-Deus G, Lopes HP, Siqueira JF Jr. Comparison of the effectiveness of three irrigation techniques in reducing intracanal Enterococcus faecalis populations: an in vitro study. J Endod 2009;35(10):1422-1427.

31. Siqueira JF Jr, Alves FR, Rôças IN. Pyro sequencing analysis of the apical root canal microbiota. J Endod 2011; 37(11): 1499-1503.

32. Duggan JM, Sedgley CM. Biofilm formation of oral and endodontic Enterococcus faecalis. J Endod 2007; 33(7):815-818.

33. Buck RA, Eleazer PD, Staat RH, Scheetz JP. Effectiveness of three endodontic irrigants at various tubular depths in human dentin. J Endod 2001;27(3):206-208.

34. Clegg MS, Vertucci FJ, Walker C, Belanger M, Britto LR. The effect of exposure to irrigant solutions on apical dentin biofilms in vitro. J Endod 2006;32(5):434-437.

35. Pawar R, Alqaied A, Safavi K, Boyko J, Kaufman B. Influence of an apical negative pressure irrigation system on bacterial elimination during endodontic therapy: a prospective randomized clinical study. J Endod 2012;38(9):1177-1181. 